\author{
T. Luke · N. Brook-Carter • A.M. Parkes \\ E. Grimes • A. Mills
}

\title{
An investigation of train driver visual strategies
}

Received: 8 August 2005 / Accepted: 9 October 2005 / Published online: 2 December 2005

(C) Springer-Verlag London Limited 2005

\begin{abstract}
Train driving is primarily a visual task; train drivers are required to monitor the dynamic scene visually both outside and inside the train cab. Poor performance on this visual task may lead to errors, such as signals passed at danger. It is therefore important to understand the visual strategies that train drivers employ when monitoring and searching the visual scene for key items, such as signals. Prior to this investigation, a pilot study had already been carried out using an eye tracking technique to investigate train drivers' visual behaviour and to collect data on driver monitoring of the visual environment, Groeger et al. (2003) Pilot study of train drivers' eye movements, University of Surrey. However, a larger set of data was needed in order to understand more fully train driver visual behaviour and strategies. In light of this need, the Transport Research Laboratory produced a methodology for the assessment of UK train driver visual strategies, on behalf of the Rail Safety and Standards Board and applied this methodology to conduct a large-scale trial. The study collected a wealth of data on train drivers' visual behaviour with the aim of providing a greater understanding of the strategies adopted. The corneal dark-eye tracking system chosen for these trials tracks human visual search and scanning patterns, and was fitted to 86 drivers whilst driving in-service trains. Data collected include the duration and frequency of glances made towards different elements of the visual scene. In addition, the train drivers were interviewed after driving the routes, to try and understand the thought processes behind the behaviour observed. Statistical analysis of over 600 signal approaches was conducted. This anal-
\end{abstract}

T. Luke $(\bowtie) \cdot$ A.M. Parkes · E. Grimes

TRL, Crowthorne House, Nine Mile Ride,

Wokingham, Berkshire, RG40 3GA UK

E-mail: tluke@trl.co.uk

Tel.: +44-01344-770495

N. Brook-Carter · A. Mills

Rail Safety and Standards Board, Evergreen House, 160 Euston Road, London, NW1 2DX UK ysis revealed that signal aspect, preceding signal aspect, signal type and signal complexity are important factors, which affect the visual behaviour of train drivers. Train driver interview data revealed that driver expectation also plays a significant role in train driving. The findings of this study have implications for the rail industry in terms of infrastructure design, design of the driving task and driver training. However, train driving is extremely complex and the data from this study only begin to describe and explain train driver visual strategies in the specific context of signal approaches. This study has provided a wealth of data and further analysis of it is needed to investigate the role of other factors and the complex relationships between factors during signal approaches and other driving situations systematically. Finally, there are important aspects of visual behaviour that cannot be examined using these data or this method. Investigation of other aspects of visual behaviour, such as peripheral vision, will require other methods such as simulation.

Keywords Train driver - Eye tracking - Visual strategy

\section{Introduction}

Following a number of recent incidents on the railways that have been attributed to errors in human performance, an increased effort has been focussed on conducting research into understanding the behaviour, and the underlying motivations of the train driver. One of these areas of research concerned the visual behaviour and performance of train drivers.

Train driving is primarily a visual task. Train drivers are required to monitor the dynamic scene visually, both outside and inside the train cab. Poor performance on this visual task may lead to errors, such as signals passed at danger. For this reason, understanding the visual behaviour of train drivers and the strategies they employ when monitoring and searching the visual scene is important. Figure 1 depicts the normal signalling 
Fig. 1 Normal four-aspect sequence of signalling. (C) Railway Safety GE/RT 8000 - S1, 2003
The normal sequence of four-aspect signalling is:

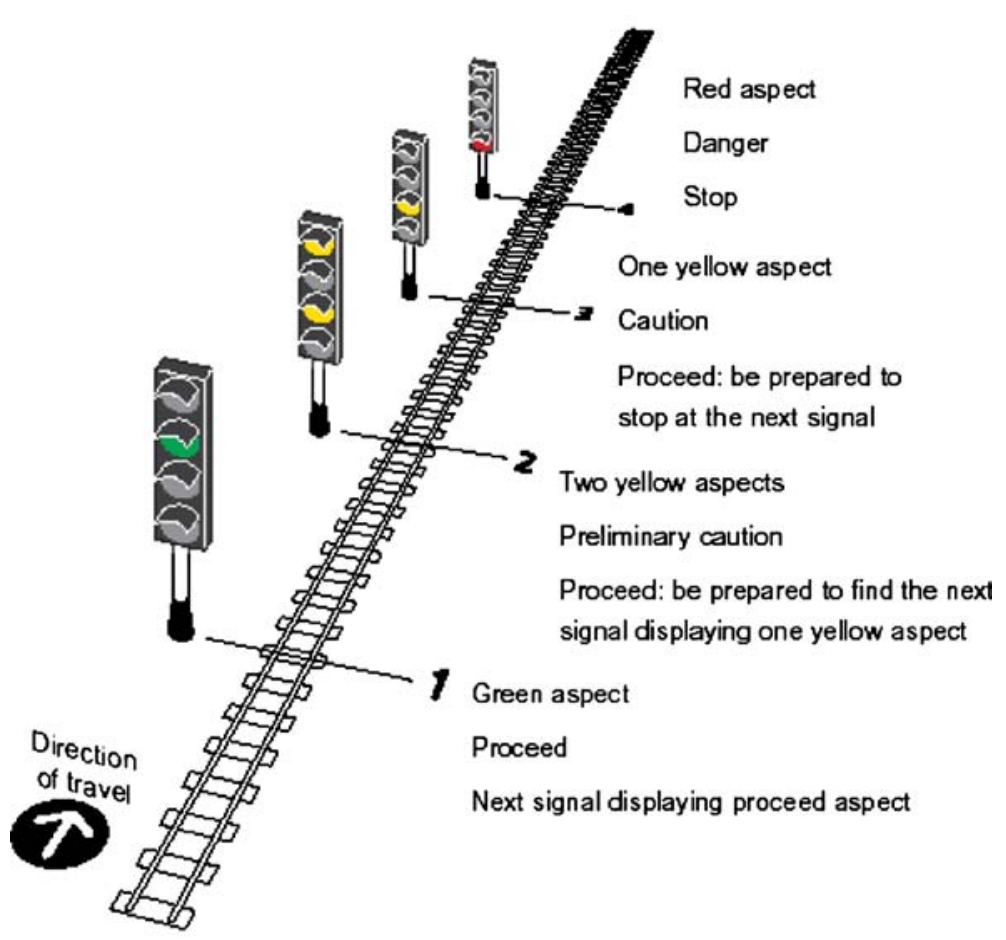

(C) Railway Safety GE/RT 8000 - S1, 2003 sequence for four-aspect signalling (Railway Safety GE/ RT 8000-S1 2003).

To date there has been very little research carried out to investigate the visual behaviour of train drivers. Only one study has been carried out in the UK. This was a small pilot study involving ten train drivers (Groeger et al. 2003), and some potential visual strategies were identified. The study showed that approximately $50 \%$ of time approaching signals was spent scanning the visual scene. The remaining time was spent fixating on railway signage and infrastructure, locations beside the track and signals. The study found that drivers looked at signals for the first time about $8 \mathrm{~s}$ before they reached them and then looked at the signals again on a number of separate occasions. About $20 \%$ of the 15 s period on the approach to each signal was spent looking at the signal. They found that cautionary signals are looked at earlier and for more time overall. Signals on gantries were looked at earlier and for a greater duration. Automatic warning system (AWS) was also found to influence driver visual behaviour. Substantial numbers of first looks at signals were made after the AWS auditory alarm had sounded.

Further research on train drivers was clearly needed to catalogue the full range of visual strategies and to identify those most effective. The work described in this paper followed on from the work of Groeger et al. (2003) and extended the methods used, and a larger set of data was obtained to provide a greater understanding of the strategies adopted. This study collected data for 86 drivers driving ten different in-service routes whilst wearing an eye tracker.

Due to the vast amount of data collected during these trials and the time-consuming nature of the frameby-frame analysis required, only a limited amount of the video footage could be analysed; therefore signal approaches were analysed in detail.

Findings from the analysis of these data are presented in relation to the impact of signal type, signal aspect, preceding signal aspect and signal complexity on train driver visual behaviour. The implications of these findings for the rail industry are discussed.

\section{Method}

\subsection{Eye tracker}

The eye tracker used during this research was a head mounted ISCAN VisionTrak ETL-500, supplied by Polhemus (Colchester, VT, USA).

The eye tracker headset consisted of a dichroic mirror, which was positioned below the eye and was transparent, an infrared illuminator which detected the pupil positions, an eye camera and a camera to film the visual scene. As shown in Fig. 2, the scene camera was positioned below the participant's line of sight. 


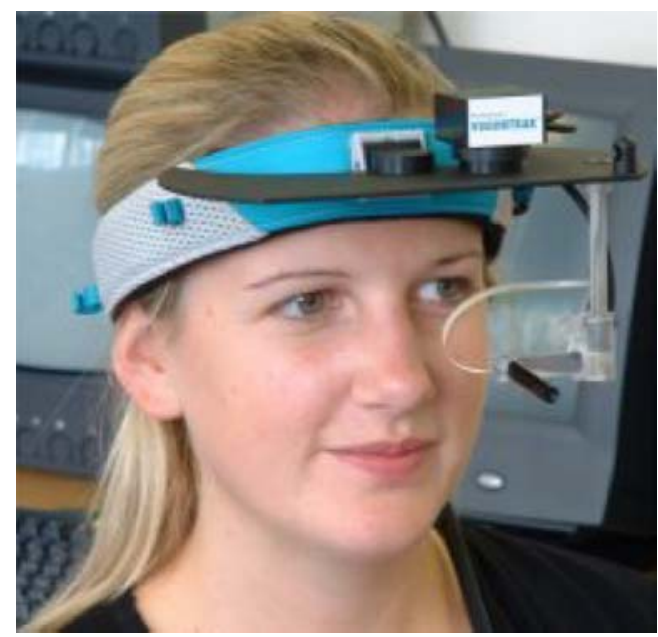

Fig. 2 Eye tracker

The tracking technique used by the system is a 120 $\mathrm{Hz}$ pupil and corneal dark-eye tracker. As the eye tracker used dark-eye tracking it was not affected by changes in lighting conditions, such as glare or darkness when driving through tunnels.

The eye tracker automatically tracked point of regard and the correlation of the raw eye position to the precise position on the scene, in real time. The image being focussed by the participant was identified via crosshairs instantaneously superimposed on the scene image. The head mounted system allowed the participant full six degrees of freedom of movement.

The eye tracker consisted of two separate sets of equipment: portable and fixed. The fixed system was set up in an office and possessed the full eye tracking software and functionality. The portable equipment carried onto the train consisted of the eye tracker headset, a Sony Hi8 video recorder, a multiplexing unit and a battery belt.

\subsection{Routes}

Ten routes were selected, based on availability and preference expressed by the Train Operating Company (TOC) involved. Each driver drove one route in both directions, with a short break in between. These routes varied in length between 25 and $50 \mathrm{~min}$. All data were collected in daytime conditions.

All journeys that were completed as part of the main trial were on normal running in-service trains, which carried passengers and were timetabled to run on a schedule. Routes included both high speed and stopping services, in rural and urban areas. Several different train units were used throughout the trials. All train cabs used were equipped with in-cab safety systems including AWS, driver reminder appliance (DRA) and train protection warning system (TPWS).

In general, the routes and cabs were representative of the UK rail network as a whole.

\subsection{Participants}

Eighty-six drivers participated in the study. Participant age ranged from 24 to 63 years, with an average age of 40. Participant train driving experience ranged from 1 month to 43 years with an average of 9.86 years. The duration participants reported driving the particular route involved in the study ranged from 1 month to 40 years with an average of 7.5 years. There were 79 males and 7 females involved in the study. The number of other routes participants reported driving ranged from 1 to 13 with an average of 5.21.

\subsection{Procedure}

\subsubsection{Calibration}

Calibration of the equipment was carried out in an office before boarding the train. This involved a five-point calibration. The advantages of calibration at a station office include the reduced time pressure under which the calibration takes place.

\subsubsection{Re-calibration}

In addition to the calibration conducted in the office, it was possible to conduct further calibration during the journey. This feature was particularly useful in cases where the driver requested adjustment of the eye tracker. Calibration on the train was conducted when stationary, usually in cases when the train was waiting at a station.

\subsubsection{The journey}

Two people accompanied the driver in the train cab; one experimenter and a Driver Standards Manager (DSM). Once the eye tracking equipment was secured and the train driver was happy to proceed, the experimenter sat on the other side of the train cab and did not communicate with the driver.

The only communication between the driver and the experimenter was in a situation, where the driver wished to discontinue involvement within the trial or during recalibration at station stops.

\subsubsection{Verbal reports}

The verbal reports took place after the drivers had completed both their drives and were back at the station office. They were shown a video clip of a section of the route they had just driven. Sections of the route for review were specifically chosen for having relatively high workloads and contained items such as complex gantry signals and poorly sighted signals. The drivers were shown two clips of their section of route, which lasted for approximately $20 \mathrm{~min}$ in total. 
The drivers were asked to carry out a commentary whilst watching the clips of the route they had just driven. The eye tracker footage displayed the driving scene from the position of the driver in the train cab. These recordings were played via the eye tracker software and therefore displayed the crosshair indicating the driver's point of regard on the visual scene. Whilst watching the clips the drivers were asked to talk through their visual behaviour and strategies with reference to the position of the crosshair on the scene. The drivers were asked to describe what they were looking at and why they believed they adopted a particular visual behaviour.

If the drivers experienced difficulties in making verbal reports and only provided brief verbalisations, the experimenter prompted the driver with probe questions such as:

'What are you looking at here?'

or

'Why are you focussing on that particular feature?'

Following the commentary, drivers were asked a series of general questions relating to their visual behaviour whilst driving. These questions are listed in Table 1.

\subsection{Verbal report data processing}

The verbal reports produced a large amount of raw data in the form of handwritten notes. The first stage of processing was to create a spreadsheet containing all comments. Each comment was then printed out on to a separate piece of card.

The method employed to structure the data was the card sorting technique (Gaffney 2000). A group of four researchers sorted the cards in two main stages. The first stage involved sorting the individual cards into an appropriate theme. Researchers, on the basis of their experience of conducting the trials, identified themes. This was done by grouping together comments relating to a particular theme such as 'approaching a station'. All comments relating to approaching a station were grouped into one theme. This was repeated until all comments were allocated to a theme. The 15 main themes identified are listed in Table 2 .

During the second stage the experimenters sorted the cards within each of the 15 themes. Within each of the themes, several strategies were identified from the
Table 2 Main themes identified in verbal report data
General visual behaviour

Looking and checking for signals

Identifying the correct signal

Problems with specific signals

Aspect-specific strategies

General hazards

Approaching/leaving a station

Tunnels

\author{
Weather conditions \\ Night conditions \\ Train speed \\ In-cab \\ Choosing braking points \\ Specific braking points \\ Specific identifiers
}

numerous comments. As well as providing many different strategies, the card sorting technique was a useful method of identifying the reason behind these visual strategies and also for identifying more general behaviours. The sorted data from the verbal reports were also arranged in hierarchical diagrams to show how different strategies and behaviours relate to each other graphically. Examples of these diagrams are included in the 'Verbal report results' section.

\subsection{Glance behaviour data coding}

The data recorded in the trials was in the form of video footage with a crosshair overlaid on the scene to depict the driver's point of regard in each frame. For the purpose of the analysis described in this paper 506 signal approaches were coded. These sections all consisted of the $15 \mathrm{~s}$ immediately prior to passing a particular signal. The coding process identified and recorded the driver's point of regard for each individual frame of video. The data were coded into a number of different glance targets; signal, track, in-cab, ahead, landscape and other. Figure 3 shows a schematic representation of the coding scheme.

Data were classified as a 'glance' if five or more subsequent frames $(0.17 \mathrm{~s})$ were observed with the same point of regard. Only glances were considered in the analysis. Other eye movements, which did not dwell on a particular target for five or more frames were excluded. The frameby-frame classification was converted into seconds and used to calculate measures of visual behaviour for each target in the scene. The measures used in analysis were: glance count, the number of glances during the $15 \mathrm{~s} \mathrm{sec}$ tion; glance duration, the average duration of a glance in seconds; total time on target, the percentage of the $15 \mathrm{~s}$ section on the particular target and time of first glance, the time between the beginning of the analysis section and the first glance at the signal.
Table 1 General questions relating to train driver visual behaviour
Are you aware of any specific things you look out for when driving this route?

Why do you think you look out for the _?

Are there any things that help you identify where you are on the route?

What visual cues do you use as braking points?

Do you look out for different things in different weather conditions?

Do you use different braking points in different weather conditions?

Do you look out for different things at night?

Do you use different braking points at night?

Do you use the same braking points now as those you were taught during training? 


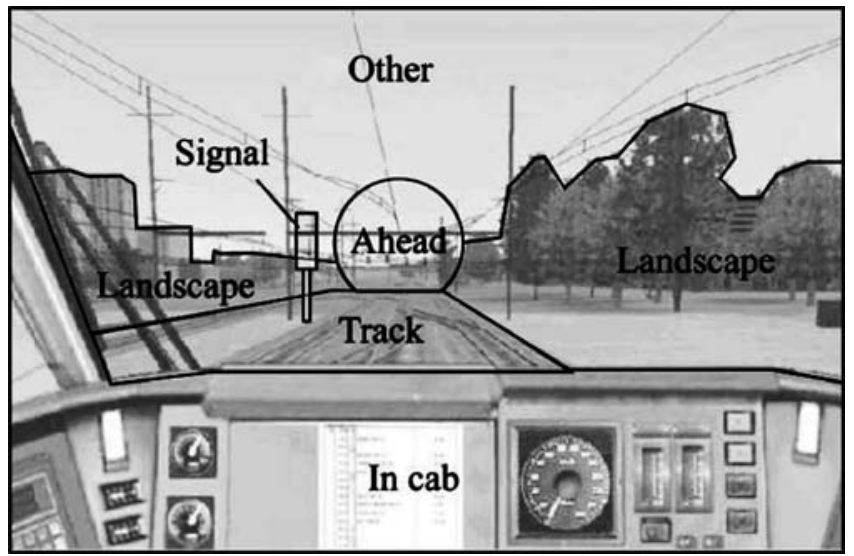

Fig. 3 Representation of the data-coding scheme

\subsubsection{Lost data}

Frames of eye tracker data were lost when:

- Participants looked outside the view captured by the scene camera

- Glare on the scene footage was too high to distinguish aspects of the visual scene

- The pupil or corneal reflection was lost due to reflections or obscuration

- The eye tracker equipment failed due to technical problems

The amount of data lost across all analysed approaches was approximately $16 \%$ (this includes driver blinks and eye closures during which the crosshair is also lost). However, the signals were in part chosen for

Table 3 Glance behaviour to the signal according to signal type analysis on the basis of the quality of the data. Approximately 400 signal approaches, which were initially selected for analysis, were not analysed due to various reasons, including poor data quality.

\subsection{Glance behaviour data analysis}

Data analysis was conducted in order to determine the effect of external factors, such as signal type and signal aspect, on glance behaviour to each target in the driving scene. Therefore, comparative statistical analysis was conducted separately for each measure of glance behaviour and for each of the targets. Unless otherwise stated, analysis was conducted using a one-way ANOVA. Post hoc comparisons were conducted using a bonferroni correction for multiple comparisons.

\section{Glance behaviour results}

\subsection{Signal type}

This analysis was conducted to determine whether the type of signal being approached affected train drivers' visual behaviour. A full range of signal types was included in the data sample. However, there were not enough examples of semaphore and banner repeater signals to consider in the analysis so they were excluded. Tables 3, 4, 5 and 6 summarise results concerned with signal type.

Signal type had a strong effect on glance behaviour to all of the main targets in the scene. Approaches to

\begin{tabular}{|c|c|c|c|c|c|c|}
\hline & & \multicolumn{5}{|c|}{ Signal type } \\
\hline & & Post & Gantry & Cantilever & Semaphore & Banner repeater \\
\hline Total glance count & $\begin{array}{l}\text { Mean } \\
\text { SD } \\
\text { Valid } N \\
\text { Statistical comparison }\end{array}$ & \multicolumn{5}{|c|}{$\begin{array}{l}\{F(2)=38.179, p<0.001\} \\
\text { Gantry vs posts, } p<0.001 \\
\text { Gantry vs cantilevers, } p=0.008\end{array}$} \\
\hline Mean glance duration (s) & $\begin{array}{l}\text { Mean } \\
\text { SD } \\
\text { Valid } N \\
\text { Statistical comparison }\end{array}$ & $\begin{array}{l}0.47 \\
0.33 \\
162 \\
\{F(2) \\
\text { Gant }\end{array}$ & $\begin{array}{l}0.60 \\
0.44 \\
120 \\
.280, p= \\
\text { vs post, } p\end{array}$ & $\begin{array}{l}0.42 \\
0.17 \\
7 \\
015\} \\
0.0015\end{array}$ & $\begin{array}{l}0.46 \\
0.32 \\
5\end{array}$ & $\begin{array}{l}0.41 \\
1\end{array}$ \\
\hline Total time on target $(\%)$ & $\begin{array}{l}\text { Mean } \\
\text { SD } \\
\text { Valid } N \\
\text { Statistical comparison }\end{array}$ & \multicolumn{5}{|c|}{$\begin{array}{l}\{F(2)=29.613, p<0.001\} \\
\text { Gantry vs post, } p<0.001 \\
\text { Gantry vs cantilever, } p=0.016\end{array}$} \\
\hline $\begin{array}{l}\text { Time to first glance (s) (higher number } \\
\text { indicates later first glance) }\end{array}$ & $\begin{array}{l}\text { Mean } \\
\text { SD } \\
\text { Valid } N \\
\text { Statistical comparison }\end{array}$ & $\begin{array}{l}10.40 \\
4.26 \\
162 \\
\{F(2) \\
\text { Gant }\end{array}$ & $\begin{array}{l}8.72 \\
4.46 \\
120 \\
.890, p= \\
\text { vs post, }\end{array}$ & $\begin{array}{l}11.62 \\
2.66 \\
7 \\
003\} \\
0.004\end{array}$ & $\begin{array}{l}6.73 \\
4.02 \\
5\end{array}$ & $\begin{array}{l}11.37 \\
1\end{array}$ \\
\hline
\end{tabular}


Table 9 Glance behaviour according to environment

\begin{tabular}{|c|c|c|c|c|}
\hline Glance target & Glance behaviour measure & & \multicolumn{2}{|l|}{ Environment } \\
\hline Signal & $\begin{array}{l}\text { Time to first glance (s) (higher value indicates } \\
\text { later first recorded glance) }\end{array}$ & $\begin{array}{l}\text { Mean } \\
\text { SD } \\
\text { Valid } N \\
\text { Statistical comparison }\end{array}$ & $\begin{array}{l}9.10 \\
4.43 \\
127 \\
\{F(1)=4.107 \\
p=0.044\}\end{array}$ & $\begin{array}{l}10.14 \\
4.31 \\
168\end{array}$ \\
\hline In-cab & Total time on target $(\%)$ & $\begin{array}{l}\text { Mean } \\
\text { SD } \\
\text { Valid } N \\
\text { Statistical comparison }\end{array}$ & $\begin{array}{l}10.33 \\
10.19 \\
196 \\
\{F(1)=9.414 \\
p=0.002\}\end{array}$ & $\begin{array}{l}13.66 \\
12.82 \\
310\end{array}$ \\
\hline Ahead & Total glance count & $\begin{array}{l}\text { Mean } \\
\text { SD } \\
\text { Valid } N \\
\text { Statistical comparison }\end{array}$ & $\begin{array}{l}5.72 \\
3.53 \\
196 \\
\{F(1)=6.987 \\
p=0.008\}\end{array}$ & $\begin{array}{l}6.65 \\
4.06 \\
310\end{array}$ \\
\hline
\end{tabular}

flashing double yellow aspects were excluded from the analysis.

Glance data indicate that drivers made more glances to the signal when the preceding aspect was double yellow than when it was green. Drivers also made shorter glances ahead and spent less time overall looking ahead when the preceding aspect was green compared to double yellow. Preceding aspect also had a significant effect on glance behaviour to the landscape. The means indicate that drivers made more frequent glances to the landscape when the preceding aspect was green (Table 13).

\section{Verbal report results}

This section presents a sample of the findings, which relate specifically to the factors, which were found to effect glance behaviour: signal type; signal complexity; signal aspect and preceding aspect. The results should not be interpreted to mean that all train drivers employ every strategy identified. They are a generalisation of the strategies described across all of the drivers who were interviewed.

\subsection{Problems with specific signals}

Drivers provided a number of comments relating to problems that are evident with some signals, including: signals being obscured by foliage or infrastructure; signals situated around bends; and high levels of complexity. Drivers described how complex signalling, such as multi-signal gantries or large numbers of signals close together, could make it difficult to identify the correct one. They also described the problems of 
Table 10 Glance behaviour to the signal according to the current aspect

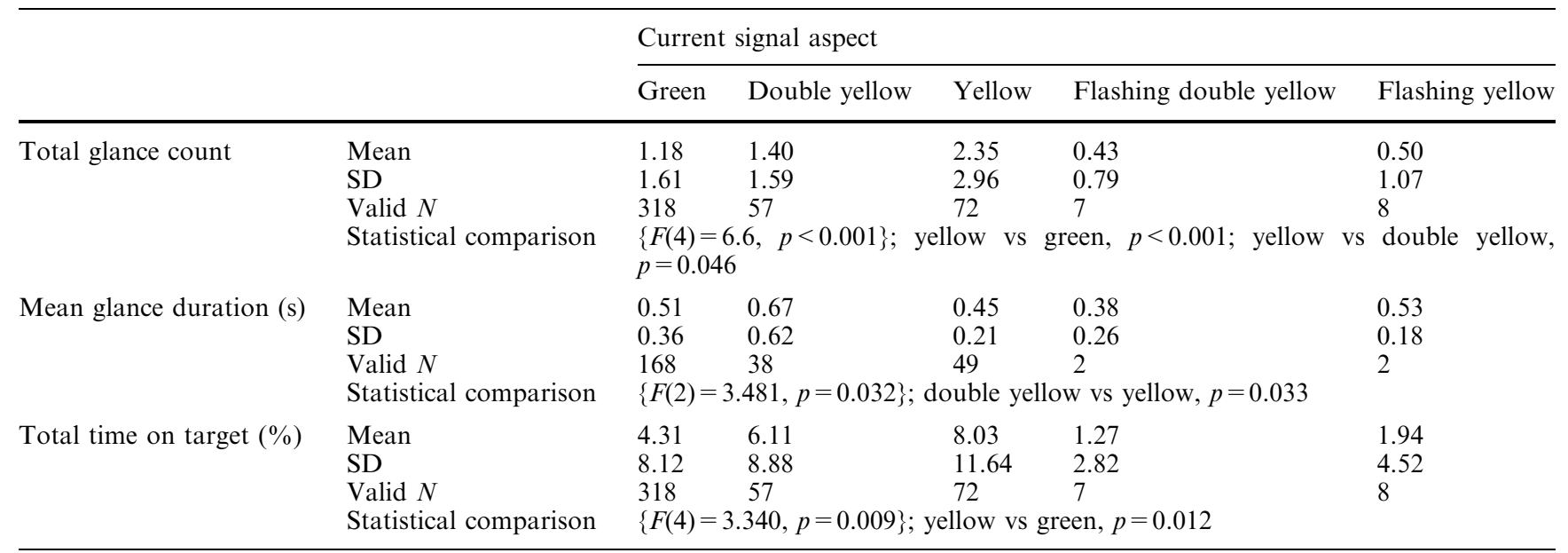

reading through (i.e. mistaking the next signal on the line to be the correct one rather than the current signal) and reading across (i.e. mistaking a signal for an adjacent line to be the correct signal). Figure 4 depicts the strategies that drivers employ to overcome these problems. These are based on the drivers' knowledge of the route. Drivers are aware of their location on the route and know when they are approaching a difficult area. They compensate for difficulty by searching for the problem signals more actively than they would for other signals.

\subsection{Identifying the correct signal}

Train drivers also described a number of more specific strategies that they use to identify the correct signal in a complex scene. Counting strategies generally relate to gantry signals. Drivers know what number line they are travelling on and count across the signals or tracks to identify the corresponding signals. Looking strategies are more general and involve looking at the scene to pick out the correct signal. This may be based on a driver's specific knowledge of where the correct signal is situated

Table 11 Glance behaviour ahead according to signal aspect

\begin{tabular}{|c|c|c|c|c|c|c|}
\hline & & \multicolumn{5}{|c|}{ Current signal aspect } \\
\hline \multirow{3}{*}{ Total glance count } & $\mathrm{SD}$ & 4.02 & 3.49 & 3.16 & 4.76 & 4.03 \\
\hline & Valid $N$ & 318 & 57 & 72 & & 8 \\
\hline & Statistical comparison & \multicolumn{5}{|c|}{$\begin{array}{l}\text { (All aspects) }\{F(4)=2.456, p=0.045\} \text { (analysis repeated with flashing aspects } \\
\text { excluded) yellow vs green, } p=0.026\end{array}$} \\
\hline \multirow{3}{*}{ Total time on target $(\%)$} & SD & 22.44 & 23.33 & 21.75 & 14.82 & 28.95 \\
\hline & Valid $N$ & 318 & 57 & 72 & & \\
\hline & Statistical comparison & \multicolumn{5}{|c|}{$\begin{array}{l}\text { (All aspects) }\{F(4)=3.307, p=0.016\} \text {; double yellow vs yellow, } p=0.033 \text { (analysis } \\
\text { repeated with flashing aspects excluded) double yellow vs green, } p=0.019\end{array}$} \\
\hline
\end{tabular}

Table 12 Glance behaviour to the landscape according to signal aspect

\begin{tabular}{|c|c|c|c|c|c|c|}
\hline & & \multicolumn{5}{|c|}{ Current signal aspect } \\
\hline & & Green & Double yellow & Yellow & Flashing double yellow & Flashing yellow \\
\hline
\end{tabular}


Aspect of signal as it is passed by train

Green Double yellow Yellow Flashing double Red

yellow

\begin{tabular}{|c|c|c|c|c|c|c|c|}
\hline Signal & Total glance count & $\begin{array}{l}\text { Mean } \\
\text { SD } \\
\text { Valid } N \\
\text { Statistical comparison }\end{array}$ & $\begin{array}{l}1.18 \\
1.61 \\
318 \\
\{F(2)\end{array}$ & $\begin{array}{l}1.40 \\
1.59 \\
57 \\
286, p\end{array}$ & $\begin{array}{l}2.35 \\
2.96 \\
72 \\
\text { een vs }\end{array}$ & $\begin{array}{l}0.43 \\
0.79 \\
7 \\
\text { le yello }\end{array}$ & $\begin{array}{l}4.33 \\
4.04 \\
3\end{array}$ \\
\hline \multirow[t]{2}{*}{ Ahead } & Mean glance duration (s) & $\begin{array}{l}\text { Mean } \\
\text { SD } \\
\text { Valid } N \\
\text { Statistical comparison }\end{array}$ & $\begin{array}{l}0.66 \\
0.48 \\
299 \\
\{F(2)\end{array}$ & $\begin{array}{l}0.86 \\
0.52 \\
55 \\
544, p\end{array}$ & $\begin{array}{l}0.79 \\
0.85 \\
68 \\
\text { een vs }\end{array}$ & $\begin{array}{l}0.48 \\
0.20 \\
6 \\
\text { le yello }\end{array}$ & 0.59 \\
\hline & Total time on target $(\%)$ & $\begin{array}{l}\text { Mean } \\
\text { SD } \\
\text { Valid } N \\
\text { Statistical comparison }\end{array}$ & $\begin{array}{l}28.99 \\
22.44 \\
318 \\
\{F(2)\end{array}$ & $\begin{array}{l}37.87 \\
23.33 \\
57 \\
204, p\end{array}$ & $\begin{array}{l}26.11 \\
21.75 \\
72 \\
\text { signific }\end{array}$ & $\begin{array}{l}17.87 \\
14.82 \\
7 \\
\text { post ho }\end{array}$ & $\begin{array}{l}9.19 \\
15.91 \\
3 \\
15\end{array}$ \\
\hline Landscape & Total glance count & $\begin{array}{l}\text { Mean } \\
\text { SD } \\
\text { Valid } N \\
\text { Statistical comparison }\end{array}$ & $\begin{array}{l}5.29 \\
4.45 \\
318 \\
\{F(2)\end{array}$ & $\begin{array}{c}3.44 \\
3.09 \\
57 \\
249, p\end{array}$ & $\begin{array}{l}4.19 \\
4.27 \\
72 \\
\text { signific }\end{array}$ & $\begin{array}{l}8.14 \\
3.44 \\
7 \\
\text { post ho }\end{array}$ & $\begin{array}{l}7.00 \\
3.46 \\
3 \\
1\end{array}$ \\
\hline
\end{tabular}

within the scene. In some cases, a specific identifier is provided by the signal, such as a large number and drivers look out for this. Finally, drivers perform extra visual checks in order to confirm that they have perceived the right signal. Figure 5 depicts the strategies used to identify the correct signal.

\subsection{Aspect-specific strategies}

Drivers provided numerous comments relating to their visual strategies in response to different signal aspects, though they did not seem to make a distinction between double yellow and yellow signals. One strategy could be described as 'defensive' and is characterised by the 'high vigilance' behaviours shown in Fig. 6 . The other strategy is more relaxed and is characterised by the 'lowered vigilance' behaviours.

Green signal strategies tend to refer to the situation of 'running on greens' rather than a single instance of a green signal. This phrase refers to the situation where a driver has encountered a series of green signals and is travelling at the line speed. During the high vigilance response to green signals drivers either adopt a strategy of 'check and re-check' or look out specifically for cautionary aspects. Reasons provided for the check

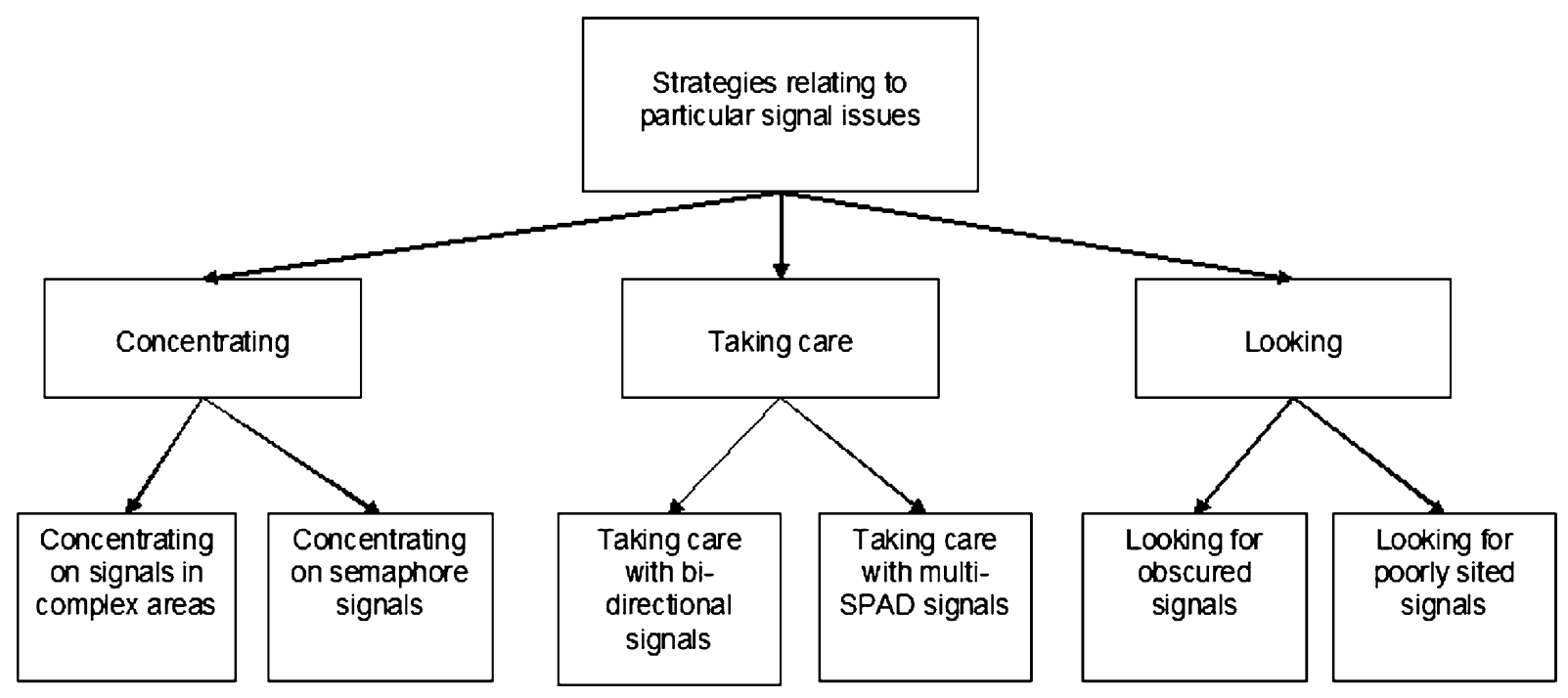

Fig. 4 Verbal report data, strategies relating to particular signal issues 


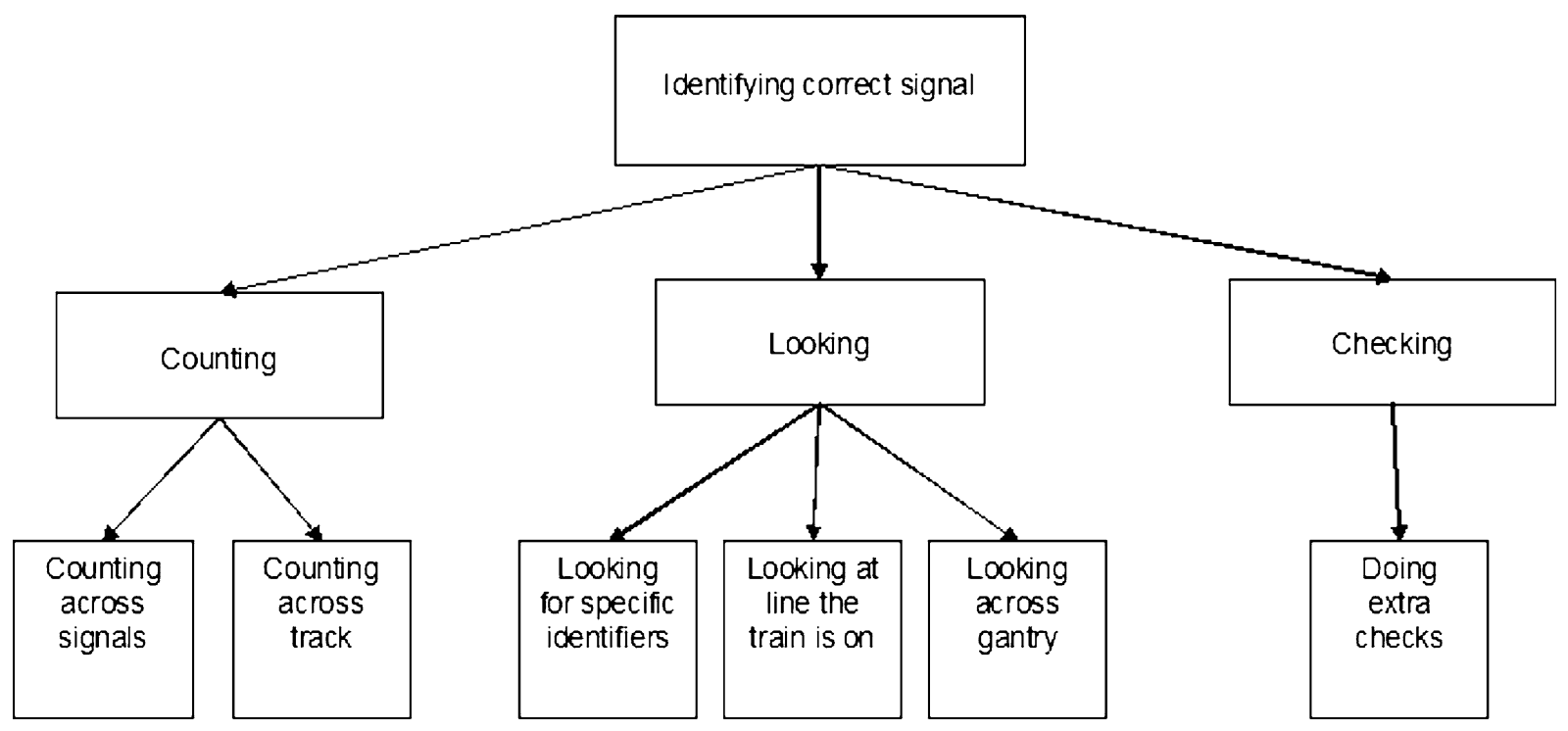

Fig. 5 Verbal report data, identification of the correct signal

and re-check strategy generally related to a driver's experience of seeing the signal change to cautionary as they are approaching it, or in some cases, from hearing an account of this situation from another driver. Drivers who look out for cautionary signals when running on green signals specifically tune their vigilance to yellow signals. Presumably this strategy is employed as cautionary signals require an immediate reaction. Drivers who described these high-vigilance strategies reported that they expected to encounter a cautionary signal at any time. In contrast, some drivers described that when running on green signal they felt that they had time to relax and look around the landscape. This strategy is likely to be the result of driver expectations based on past experience. Drivers often reported expecting particular signals to be a particular aspect.

When drivers encounter a cautionary signal they attempt to formulate an explanation for it. One possible explanation is that they are following a slower train. Drivers form an expectation of whether they will have to

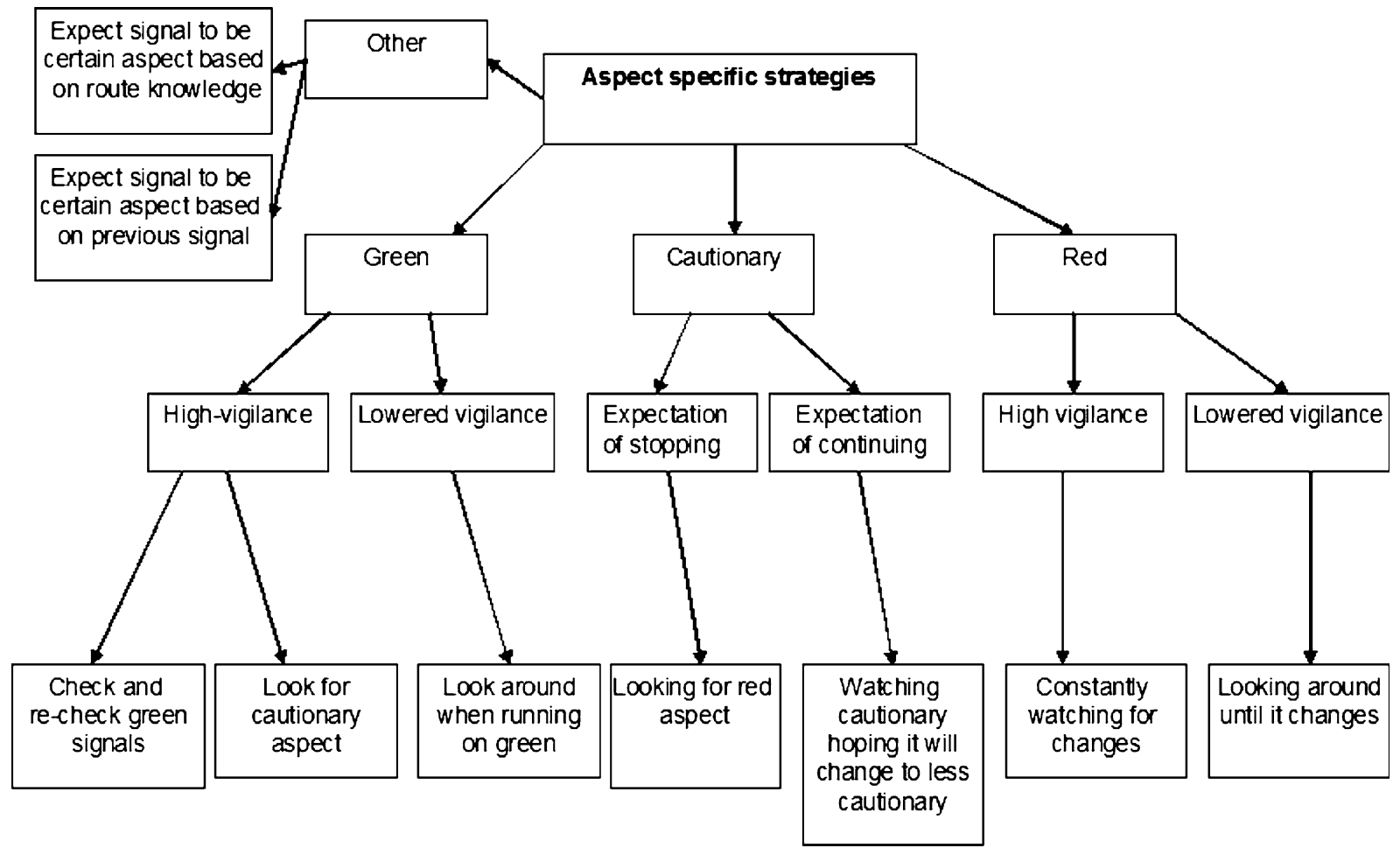

Fig. 6 Verbal report data, aspect-specific strategies 
stop according to the normal signalling sequence or whether they will encounter a sequence of cautionary signals which allows them to continue. This expectation appears to have an effect on drivers' visual strategies. If drivers expect to stop they tune their search towards red aspects. If drivers expect to continue they monitor the signal waiting for it to change to a less cautionary aspect.

Finally, during the verbal reports drivers often referred to expectations about the signal based on the aspect of the previous signal. This is unsurprising as train signalling follows a rigid sequence. However, given the impact of expectation on train drivers' visual strategies, preceding aspect is likely to be an important factor.

\section{Discussion}

\subsection{Summary and interpretation of results}

\subsubsection{Signal type}

Signal type was found to have a strong effect on visual behaviour. When drivers were approaching gantry signals they looked at the signal more often, for longer, and for a greater percentage of the time overall compared to when approaching post or cantilever signals. Drivers also appeared to glance at gantry signals earlier than post or cantilever signals. These results were consistent with the findings from Groeger et al. (2003).

These results also concurred with the verbal report data. Drivers described different methods that they use to identify signals on complex gantries. The strategies that were employed to identify the correct signal on a gantry, such as counting across and repeated checking, required longer, more frequent and possibly earlier glances towards the signal.

These results appeared to indicate that drivers directed more attention to the signal when they were approaching a gantry signal. The finding that drivers spent more time looking ahead and less time looking at the landscape when they were approaching a gantry signal compared to a post signal, further supported this conclusion. This implied that drivers were more focussed on searching for the signal when approaching a gantry.

There were very few differences between post and cantilever signals, though drivers looked more often and spent longer overall looking at the track when approaching cantilever signals compared to when approaching post signals. Verbal report data did not indicate that drivers find cantilever signals to be particularly difficult or different from any other type of signal. Cantilever signals were generally situated above the track rather than to the left side like posts. This may account for why drivers spent more time looking at the track when approaching cantilever signal; drivers may have been using it as a marker or cue to locate the signal.

\subsubsection{Signal complexity}

Drivers made more frequent glances to gantries with six signals on than those with only two signals on. Drivers also looked at gantries with six signals earlier than those with two signals. In the verbal reports drivers stated that they had to focus more on the signal in complex areas, these statements support the results found in the glance data.

Drivers made longer glances ahead and spent more time overall looking ahead when approaching two signal gantries compared to gantries with five or six signals. This result was inconsistent with other findings that suggest that drivers looked ahead more in areas where they expected complex situations. From the verbal report data it would be expected that drivers would search ahead more to identify signals on a complex gantry. It is possible that some other external factor, such as the position of two signal gantries, which was not considered in the analyses, had an impact. For example, two-signal gantries may be specifically associated with another route feature that also affects drivers' visual behaviour.

\subsubsection{Signal aspect}

Approaches to different signal aspects were compared. Yellow signals were glanced at more often than green and double yellow signals. Yellow signals were also looked at for a greater percentage of the time overall than green signals. Glances to double yellow signals were longer on average than glances to yellow signals. Signal aspect did not appear to have an effect on the time of the first glance at the signal. However, a limitation of the eye-tracking technology means that the first glance at the signal may not have been captured in the data.

Groeger et al. (2003) found that cautionary signals were looked at earlier and for more time overall than green signals. The findings from this analysis were consistent with the finding relating to the overall amount of time spent looking at the signal. The data indicated that cautionary signals are looked at more often and for more time overall. However, the data from this study could not confirm whether cautionary signals were glanced at earlier than green signals. There was also some inconsistency with the Groeger et al. (2003) findings in that glances to double yellow signals were longer on average than those to single yellow signals.

The Wickens (1992) visual sampling model stated that safety critical targets would receive greater visual sampling than non-safety critical targets. This provided a possible explanation for the overall trend towards greater attention to cautionary signals. Single yellow signals in particular indicated to the driver that they might soon need to stop at a red signal. The safety implications of missing a red signal would be serious. If 
a yellow signal was missed the chances of failing to stop for a red signal would be increased and may explain why cautionary signals received greater sampling than green signals.

Drivers spent significantly more time overall glancing ahead when approaching double yellow signals compared to when approaching yellow or green signals. Verbal report data suggested that drivers formed expectations when they encountered a double yellow signal regarding whether they would need to stop or whether they were following another train and would not need to stop. This behaviour may have represented the drivers' attempts to gain information, which could be used to form this expectation. Alternatively, this effect may be the result of the demands of the drivers' response to the double yellow signal. For example, drivers may have looked ahead more when they were slowing down.

When approaching green signals drivers made more glances to the landscape and spent a greater percentage of time overall looking at the landscape than when approaching double yellow signals. This may represent generally more relaxed behaviour in response to green signals. Some drivers described in the verbal report that when 'running on greens' they tended to relax and look around more.

\subsubsection{Preceding aspect}

The effect of the preceding aspect on train driver visual behaviour was examined. When the preceding aspect was green, drivers made fewer glances to the current signal compared with when the preceding aspect was double yellow. Yellow or double yellow signals were indicative of a red signal in the distance and would therefore prompt more caution from the driver than green signals. Preceding aspects that were cautionary seemed to prompt the driver to pay more attention to the next aspect.

When the preceding aspect was double yellow, drivers made longer glances ahead than when the preceding aspect was green. The verbal reports suggested that this time looking ahead could have been the drivers searching ahead for the next signal. We infer that, when the preceding aspect was double yellow, drivers made longer glances ahead to search for the next signal.

In general, the findings for preceding aspect are not as strong as would be expected on the basis of the verbal report data and the previous findings of the Groeger et al. (2003) study. The verbal report data suggested that this might be due to the fact that it is not just the preceding aspect that affects drivers' expectations and visual behaviour. The sequence of aspects that the driver has encountered and their experiences of numerous past situations on the same route also appear to play an important role in determining their visual behaviour and strategies.

\subsection{Implications}

The finding that gantry signals were looked at more than other kinds of signals appears to suggest that these signals required more of the driver's attention in order to obtain the necessary information. This may have implications for infrastructure design if the aim is to provide drivers with signalling information with the least possible workload on the driver's part. Verbal report data contains examples of the strategies used by drivers to identify the signal in complex situations. These included counting across signals and using the specific identifiers, which were provided on some signals. It may be that providing the driver with identification support on those signals that do not currently have it, such as numbering, would reduce the difficulty of identifying the signal.

The results for the signal type comparisons also seemed to suggest that drivers compensate for the difficulty on approach to gantry signals by looking ahead more. It was assumed that this strategy was advantageous in providing early detection of the signal. This was further evidence that route knowledge, in terms of knowing the current position on the route and the important features being approached, was extremely important in train driving. This evidence from the verbal reports suggested that knowledge of the signalling sequence was particularly important. This has implications for the design of training programmes in that emphasis on route knowledge and signalling in particular should be maintained.

The results showed that signal aspect has an effect on driver visual behaviour. In particular, drivers seemed to pay more attention to cautionary signals. This is a positive behaviour that is likely to reduce the chances of missing a red signal. Drivers reported watching cautionary signals in case they changed to red or in the hope that they would change to less cautionary. However, evidence from the verbal reports implies that some drivers may have altered their concentration levels when they expected to be running on green signals for a period of time. It is unclear whether this behaviour is positive or negative. It may allow drivers to conserve energy for periods of high workload, beneficial as drivers often work long shifts and on long intercity journeys breaks may be irregular. Alternatively, it may mean that drivers could miss safety critical targets in these periods of green running.

The role of expectation about future events appears to be important to the driving task, for example, the expectation of intercity drivers that they will continue on green signals. There is a slight concern that drivers can form faulty expectations, which could lead to errors in certain situations. In general, this translates to a need to ensure that the driving task is designed such that the driver maintains vigilance of critical items throughout periods of green running, and that informational support or cues are given to ensure that 
drivers' expectations are not faulty. It is important to preserve the periods of lower workload in the driving task, especially for drivers on long shifts and journeys.

\subsection{Limitations}

It should be noted that although the eye tracker provides a rich source of data relating to the visual behaviour of the participant, it does also possess a number of limitations. The eye tracker tracks the fixation point of the participant. However, this did not always directly relate to the direction of the participant's attention. On some occasions, the participant may be attending to stimuli in the peripheral vision or cognitive or auditory inputs.

The experimental conditions imposed on the driver, such as wearing the eye tracker and the presence of a DSM and experimenter in the cab, may have caused the driver to alter visual behaviour during the trial. In other words, the train driver may be on 'best behaviour' and therefore the recorded visual behaviour may not reflect what the train driver would normally do. Naturally this is of concern and to some extent unavoidable with the head mounted system. However, there is a limited time period for which a human can concentrate and control his/her visual behaviour and after a short period of wearing the eye tracker, normal, automatic visual behaviour would be expected. Further, once train drivers are immersed in the train driving task, they are unlikely to be focussed on controlling their visual behaviour, but instead will be concentrating on operating the train.

A head mounted eye tracker was the only sensible option for use on in-service trains. Approximately $16 \%$ of the frames of data in the analysed approaches were classified as lost because the point of regard could not be determined.

In addition, the scene provided by the scene camera was not as high quality as that provided by the human eye. Aspects of the scene may have been detected in the distance by the participant before they were visible to the experimenter analysing the video data. It may therefore appear that stimuli in the distance were detected later than they are in reality. In addition, it is difficult to distinguish between the presentation of different signal aspects (although these data were recorded during the trials). Further, the scene camera did not record the scene well in bright light and stimuli could not be distinguished.

The main implication of this limitation is that the measure, time to first glance, may not be the first time that the driver looked at the signal in reality. It is possible that the driver looked at the signal much earlier than this. In many cases it is possible to see the next signal and distinguish the aspect immediately after passing the previous signal. Verbal report data suggested that drivers attempted to look at the signal as early as physically possible. For example, drivers referred to searching for the next signal as they come around a bend.

Due to the resource-intensive nature of analysing the large amount of video data captured by the eye tracker, a number of people were employed to analyse the data. They were fully trained in the coding scheme. A data entry tool was built to ensure that only valid data codes could be entered and checks were made during the data coding process to ensure that coding was accurate. However, subjective decisions regarding the driver's point of regard were sometimes necessary and there may have been some differences in the decisions made by different operators processing the data.

\subsection{Areas for further investigation}

The number of signals on a gantry was used as a measure of complexity. However, this is only a single measure of complexity and complex environments also exist where there are no gantry signals. Further work should try to take into account more aspects of complexity in the driving scene. This would allow more detailed description of what factors make the drivers' jobs more difficult and would provide a better indication of how to improve the railway infrastructure to compensate.

Verbal report data indicates that driver expectations play a crucial role in determining their visual behaviour and their actions. These expectations are built on evidence not just from the previous aspect but from the sequence of previous aspects as well. Future analysis could look more deeply at the preceding sequence of aspects. This analysis might also consider the role of other factors relevant to the driver's expectation in determining visual behaviour. Deeper understanding of these factors will allow better training to be developed that would help to ensure that train drivers form accurate and useful expectations.

The data collected in this research are useful for investigating many areas. However, there are some areas that cannot be explored using this type of methodology. For example, the role of peripheral vision has been found to be important in car driving research (Waldram 1960; Moore 1968; Helander and Soderberg 1972). It is possible that peripheral vision is also an important factor in train driving but it cannot be investigated using current eye tracking technology as it only tracks point of regard. Other methods such as simulation may provide a way to investigate this type of issue.

\section{Conclusion}

Statistical analysis of 506 signal approaches was conducted. This analysis revealed that signal aspect, preceding aspect, signal type and signal complexity are important factors, which affect the visual behaviour of train drivers. Verbal report data revealed that driver 
expectation also plays a significant role in train driving. The findings of this study have implications for the rail industry in terms of infrastructure design, design of the driving task and driver training.

However, train driving is extremely complex and the data from this study only begin to describe and explain train driver visual strategies in the specific context of signal approaches. Further analysis is needed to systematically investigate the role of other factors and the complex relationships between factors. There are also many other areas to explore in further analysis, such as visual behaviour in situations other than signal approaches. Finally, there are important aspects of visual behaviour that cannot be examined using this data or this method. Investigation of other aspects of visual behaviour, such as peripheral vision will require other methods, such as simulation, to be employed.

\section{References}

Gaffney G (2000) Usability technique series. Information \& Design. http://www.infodesign.com.au

Groeger JA, Bradshaw MF, Everatt J, Merat N, Field D (2003) Pilot study of train drivers' eye-movements. University of Survey Technical Report for Rail Safety and Standards Board, London

Helander M, Soderberg S (1972) Driver visual behaviour and electrodermal response during highway driving. Goteborg Psychological Reports, vol 2, no. 4. University of Goteborg, Goteborg

Moore RL (1968) Some human factors affecting the design of vehicles and roads. Proc Inst Mech Eng 183(3A):79-92

Railway Safety GE/RT 8000 - S1 (2003) Signals and indicators controlling train movements. http://www.rgsonline.co.uk/ docushare/dsweb/Get/Rail-5133/S1.pdf

Waldram JM (1960) Vision and eye movements of motor drivers. New Scientist 8(208):1264-1267

Wickens CD (1992) Engineering psychology and human performance, 2nd edn. HarperCollins, New York, NY 